\title{
RESULTS OF AN INVESTIGATION ON THE PRESENT STATUS OF HIGH SCHOOL PHYSIOGRAPHY.
}

\author{
By Charles E. Peet, Chairman, \\ Lezris Institute, Chicago. \\ Preliminary Statement by Chairman.
}

The committec was continued from last year to discover the schools that, in the first-year high school physiography, produce results recognizable in college, and to study their methods. I.etters were sent to the same college, university and normal school instructors that contributed the information reported last year. About one-third of the number sent replies, which may or may not mean that those not replying had nothing to add to their former contributions.

1. It was asked if any marked improvement in the results of the high school physiography in the last three years had been noted. Two-thirds of the replies were in the negative. The other third expressed the opinion that there had been a slight improvement, but in no case was it considered so great or so general as to justify the division of the college classes into those with entrance credit in physiography and those without it. At least one reply was based on the fact that the number of trained teachers is increasing rather than on improvement directly observed.

2. The names of the schools were requested where it was known that the course in physiography in the first year of the high school is so good that the results are recognizable when the sttdents get to college. Two schools mentioned as coming the nearest to answering this description were in each case in the town in which the corresporident lived. One answer says: "Some students from the Chicago high schools have carried over some of the results of their work in physiography. In many cases, they do not remember a great deal, but they have a feeling for the subject, which enables them to acquire related material easily. Individual students from St. Louis, Minneapolis and various towns of Wisconsin and other states have had similar power."

3. The names of schools were requested in which the work is so good that it might be recognized by placing the students with entrance credit in physiography in separate classes in college from those who have not this credit. Ten schools were mentioned; of which five in Indiana were mentioned by one man and four in Colorado by another, the schools of one city in Ohio by another. 
Another said: "I cannot supply you with a list of schools whose product is so universally good that the high school foundation might be recognized. I know of several good teachers who are doing excellent work, but the students do not seem to retain the subject matter. Physical geography is only one year nearer than the geography of the grades, and in neither case do the pupils seem to retain any great knowledge of the facts. What we look for at the present time is that the students who come to tis have some ability to apply themselves intelligently and to think constructively. So much depends upon the individual student, rather than the nature of the cotrise, that it does not seem probable that we shall be able to pick them out on the basis of previous work. I would prefer to use the ability of the student as a basis. Unfortunately, we cannot do this at the present but it would be an excellent way to check your proposition."

To sum up the results of this search: There are many schools that are doing good work in physiography in the early years of the high school, but there is little of the product recognizable three or four years later. We have been unable to learn of schools that produce in the first year of the high school an impression so lasting that they can serve as models to follow for this purpose. The schools that are doing good work and are recognized as doing good work have been regtilarly represented in these meetings and in the meetings of similar organizations in different parts of the country.

It was a surprise last year to learn that generally so little of the high school physiography was left when the student gets to college. It has been known for a long time, of course, that high school results were criticized, but we have thought that they were the results of the other fellow that were referred to.

The attitude at first concerning this poor showing is one of amused unbelief and one is likely to ask about a man making such statements: "What's the matter with him?" Then the attitude changes to one of doubt. So many say the same thing, there must be some truth in what is said. Then comes the conclusion that the statements are true. And finally: "Of course! We couldn't expect it to be otherwise."

The experience of some instructors who have passed from the high school to the university and there received their own high school students is very instructive. Professor Atwood reported his experience to a conference at the University of Chicago several 
years ago. Another instructor in physiography in one of the great universities in the Middle. West told me that the students he taught in the high school before going to the university were no credit to him when they came to the university. His high school principal was very much surprised that this should be true of the work of a teacher who was so full of enthusiasm for his work and so well prepared that he was called to the State University.

There very likely are those among us who have been careful not to omit anything from the course for fear that it might be a disadvantage to some student after he gets to college. It is well for us to know that the high school foundation is not so important that the omission of a topic here and there will cripple the student in his college work in this subject, and that these omissions will not "introduce confusion and lower the standards of work in the universities," as some one has recently said about the introduction of elementary science in the high school. It is well for us to know the truth. The truth makes us free to shape our work according to the needs of our students.

It seems that the college man has little interest in the knowledge we impart. His great interest is in the mental development, for which the teachers of physiography are responsible but for a small fraction of the total.

It is well for us to know that the esteem in which the high school man is held by the college man can not be high if it is based on the product sent to college. It is by the work we do for the student while we have him, not what there remains four years later, that we may fairly be judged it seems.

The report of the high school results in physiography were so discouraging, to give them proper value it seemed desirable to learn what are the results in the other high school sciences. Misery loves company. Are we alone in our misery? The same questions which had been sent to college instructors in earth science were sent to the college instructors of other sciences commonly represented in the high school curriculum. Here are some of the replies:

\section{Results in High School Botany.}

"We do not find that the college or university course in botany can be built on the foundation laid in the high school.

"We do not distinguish in our elementary course between those 
students who have had high school work in botany and those who have not. Our experience has been that there is practically very little difference between these two classes in their ability to master the subject as presented in a university.

"My answers to the foregoing questions do not, I think, necessarily imply that the high school work in botany is unsatisfactory. The purposes of the high school course in the subject given in the first or second year of high school are radically different from the purposes of a university course. The method of treatment in the two should be equally different, and it seems to me that it follows that the one cannot in any real sense be a preparation for the other. Even if more similarity between the two were possible, the lapse of three or four years between the time of taking work in botany in high school and the time of starting it in the university would destroy any possible continuity. It is true, of course, that the high school work in botany is by no means satisfactory. The same, I think, may be said of the high school teaching in any subject. I am inclined to think that the greatest source of trouble is in the poor quality and poor preparation of the great majority of high school teachers. Improvement must come, if at all, more through a raising of the standard required for entrance into high school teaching than through any possible amount of tinkering with the content or arrangement of high school courses."

Another says: "My introductory biology is so different from the high school work that the high school botany does not seem to matter. The high school botany seems to be all right for training, but the students do not seem to know any botany. They forget it all before entering college."

\section{Results in High School Chemistry.}

Concerning chemistry, one reply says: "College classes are divided into separate divisions for those who have and those who have not had the subject in high school. The high school work is unsatisfactory in the lack of knowledge of the subject except iti some special cases, generally from some of the larger schools. They know some general things about the study, but after the first six weeks of elementary points the subject is practically new to them. The chief reason for the unsatisfactory results is the quality of instruction in the high schools. In the larger schools where good instruction is given, the students are satisfactory. Fully fifty per cent of the students have, however, been under very inefficient instruction." 
Another says: "We do not build on the high school work in chemistry. Two years ago, we had those with high school credit in the subject in a separate division, but we have discontinued this, for at Thanksgiving time there was no visible difference between the sections. The fact that we can not build higher college courses in chemistry upon high school chemistry is not a criticism of high school work in any way. We feel that the high school must principally serve those that do not go to college.".

\section{Results in High School Physics.}

Concerning physics, we have the following letter: "In reply to your recent inquiry, $I$ take pleasure in saying that in this university we do differentiate between the different preparations which our students have had in the various high schools, and that we have one course of physics to which we admit only those who have had the training of the better and higher high schools, and an entirely different course for those who have had less extensive preparation. Into the latter class are admitted also a few students who have never before taken the subject of physics, but this number is so small as to have but little effect.

"I heg to say also, in reply to your third question, that there is one great lack which I think the high school could remedy, and which I hope you will do what you can to correct, and that is teaching the students to think, and especially teaching them how to study. My greatest diffictilty with students, as they come to me from the high schools, is that they do not know how to study, and I find that fully a third of the year goes by before these stidents know what study means, or how to apply themselves, with their minds concentrated assiduously upon what they are doing."

The progressive improvement in results from the earlier years to the later years of the high school is an interesting fact and is, of course, just what would be expected under the present arrangement of isolated sciences. Although the replies are not gathered from a wide area, and in large numbers, these facts are probably representative. They are in accord with information obtained through conversations with instructors in these subjects.

The statements show that all the high school sciences suffer from a common malady-poor instruction. But in all subjects it is recognized that there is some good instruction. It seems that the results of the sciences in the early years of the high school are negligible, that those of the later years are recognizable, but that in general the students are deficient in thinking power. 


\section{RePORT OF The COM Mittee.}

A number of reasons for poor results in high school physiography were given in the answers to the questionnaire published last year. The summary is as follows:

1. No definite aim.

2. High schools attempt too much. They are attempting the impossible. a. There are too many subjects.

$b$. Too many things are taught under the name of physiography:

3. Immaturity of the student and his ignorance of physical science ordinary geography.

4. The subject is too difficult and abstract, and is inappropriate for firstyear work. The texts are too technical.

5. Teachers do not understand the subject.

6. Teachers do not have an interest in the subject.

7. Teachers are untrained.

8. There is too little field work. The work is too bookish.

9. The laboratory and illustrative material are inadequate.

10. Facts instead of principles are taught. Descriptions instead of solutions of problems are required.

We would add that one great disadvantage from which the physiography has suffered has been its isolation. It has not been related to the subject which the student has taken in the grammar school, and oftentimes it has not been related to the experiences of daily life of the student. This is especially true in large cities with students who have had no opportunity to travel and where the difficulties of field work are so great that it is hopeless to expect progress along this line. This isolation has not been relieved by use of the knowledge obtained in its study in the subjects studied later in the high school. The knowledge commonly has not been used enough to give the student an appreciation of its value to him.

It is one of the merits of the movement to expand the course in high school geography to include more of the human relations, that it gives the student a chance to use his knowledge of the physical geography, and by so using it he will come to appreciate it. But unless it goes beyond this, unless we secure the cooperation of our fellow teachers in the later years of the high school in getting these young people to use this knowledge in their later work in science and history and literature, we may be sure that as now, there will be little left at the end of the high school course. The expansion of the course upward into the study of life-and especially of man and his relation to his environmentis a big step in advance.

There has been no time in all its history when geography could be taught to such an advantage as at the present. With the mov- 
ing picture, the lantern sfide, and the traveling museum, the world can be brought right into the schoolroom.

But those who expect lasting results from it in the immaturity of the early years of the high school are doomed to disappointment. This expansion of the course in physical geography answers the student's question of the value of the subject to him, but it does not make the knowledge perpetual. I speak from fifteen years' experience with this sort of expansion of the course in physical geography.

If this country ever adopts a system of universal military training, the opportunity will come for the boy to use his knowledge of physiography, and it will then be recognized that a service to the country is rendered by training the student to read the topographic map. In the Russo-Japanese war, General Kuropatkin complained that the Colonels even in his army could not read the maps, not to mention teaching others to read them.

The truth of the matter is that the great difficulty with our work in the city is to get the student in contact with nature. There is not money enough to carry on the work in the way it should be carried on. A system of summer camps for military training, in which training on topographic work enters so largely, could solve the problem of efficient instruction in physiography. It would came at a time when the outdoor life would be of the greatest value to the growing boy and at a time when his summers are otherwise of the least value to him. Until we get help in some such way, there is little hope for much development in the direction of work in the field for the children in large cities.

One reason for the failure of physical geography where it has been a failure is the surprising one that it has not been recognized that the student and his interests are in large part a response to his environment. The great things in the whole problem-the student himself and his interests-have been little considered. There is no reason why the physiography courses in different localities should be alike. So far as the colleges are considered, we are free to adapt the work to our students without any regard whatsoever to anything else. No subject has any right in the high school curriculum except as it justifies itself by its results.

There can be no doubt that the poor preparation of the teacher is responsible for much of the poor results in our high school geography. No census has ever been taken which would show the preparation of all the instructors in this subject in any one state so far as we are aware, but questionnaires have probed this matter 
in Illinois, Indiana, Michigan, Iowa and other states. The results of these different questionnaires are so harmonious that there can be no doubt of the facts. Yet it is doubtful if the resuits would be generally recognizable in college, even if all the instructors were as well prepared to teach the subject and were as good teachers as the best. The truth of the matter is, as the majority of the college men admit, that it is unreasonable to expect these fourteen- and fifteen-year-old children to retain for three or four years much of that which they learn in the first year of the high school and never put to use.

Last year, the attempt was made to learn whether the physiography is gaining or losing in the schools, by a questionnaire sent to schools in the Middle West that had adopted Clark's General Science for a textbook. Sixteen per cent of those replying to the questionnaire had dropped the physiography. In thirty-five per cent of the schools replying to the questiannaire, the position of the physiography had been affected by the introduction of the general science-that is, the subject had either been dropped, cut to one-half year, or changed to another year. The number of schools giving general science courses this year, as near as can be estimated-and it is only a rough approximation-is in the neighborhood of 3,000 or 4,000 . Taking the smaller figure, if the same ratio holds good, physiography has been affected in more than 1,000 schools, and of these 500 have dropped the physiography, and 300 have cut the course to a half year. It is probable, however, that the ratio of the number of schpols in which physiography is affected to the total number adopting general science is larger, for several of the newer texts are more physiographic in their nature, and the publishers say they are displacing physiography.

Of one book, however, the publishers say that in sixty per cent of the cases it is not displacing another science, but where it is displacing another science it often is agriculture, biology, botany or zoology. The exact situation should appear in the statistics of the Bureau of Education. These rough approximations obtained from the different publishers of general science texts suffice to show that a rapid change is taking place. That physiography is to be most affected by the change there is little doubt.

Charles Emerson Peet, Alison E. Aitchison, 